\title{
Determinants of Vietnamese international student satisfaction in Taiwan universities
}

\author{
Alang Tho ${ }^{1 *}$ \\ ${ }^{1}$ International University, Vietnam National University Ho Chi Minh City, Vietnam \\ *Corresponding author: alangtho@ @omiu.edu.vn
}

\begin{tabular}{|c|c|}
\hline ARTICLE INFO & ABSTRACT \\
\hline $\begin{array}{l}\text { DOI:10.46223/HCMCOUJS. } \\
\text { soci.en.11.1.1889.2021 }\end{array}$ & $\begin{array}{l}\text { This paper aims to explore factors impacting Vietnamese } \\
\text { international students' satisfaction in Taiwan universities. The } \\
\text { study was based on a process design of two sub-studies. Study } 1 \\
\text { was qualitative research with focus group discussion, and open- } \\
\text { ended survey questions were applied to explore essential factors } \\
\text { of Vietnamese international students' perception of their } \\
\text { satisfaction. Study } 2 \text { was a quantitative study in } 20 \text { Taiwan }\end{array}$ \\
\hline Received: May $23^{\text {rd }}, 2021$ & universities, in which 192 Vietnamese students participated to \\
\hline Revised: June $18^{\text {th }}, 2021$ & answer the formal questionnaires. In this Study 2 , a statistical \\
\hline Accepted: June $21^{\text {st }}, 2021$ & $\begin{array}{l}\text { procedure was employed to analyze the data. The findings from } \\
\text { Study } 1 \text { indicated that instructor, learning material and facility, } \\
\text { dormitory services, and extracurricular activity constitute } \\
\text { Vietnamese international students' satisfaction in Taiwan } \\
\text { universities. Findings from Study } 2 \text { showed that Vietnamese } \\
\text { students are satisfied with these factors. While instructor, } \\
\text { dormitory service, and extracurricular activity were considered }\end{array}$ \\
\hline Keywords: & strong predictors of these students' satisfaction, learning \\
\hline $\begin{array}{l}\text { higher education satisfaction; } \\
\text { Taiwan universities; Vietnamese } \\
\text { international students }\end{array}$ & $\begin{array}{l}\text { material and facility were relatively low. Also, it found that } \\
\text { scholarship-sponsored students had lower satisfaction than self- } \\
\text { supporting students. These findings could provide theoretical } \\
\text { and practical implication as it addresses the lack of research on } \\
\text { international students' satisfaction with universities in host } \\
\text { countries. Also, practitioners could find interesting points from } \\
\text { this paper to design marketing strategies for international } \\
\text { student recruitment. }\end{array}$ \\
\hline
\end{tabular}

\section{Introduction}

Taiwan government has implemented many policies to gain 130,000 international students studying at Taiwan universities, making the country become the education hub in the Asia region (Ministry of Education Republic of China (Taiwan), 2021). To date, international students in Taiwan come from 117 countries, and the top five nations are Malaysia, Vietnam, Indonesia, Thailand, and the Philippines (Ministry of Education Republic of China (Taiwan), 2021). Particularly, Vietnam has now become a primary source of international students for Taiwan universities every year. The number of Vietnamese students in Taiwan's universities has increased exponentially from a mere 01 student (the academic year 1987 - 1988) to 17,421 students in 2019 (Taiwan News, 2020). These may predict that the number of Vietnamese students would be increasing shortly, since the Taiwan's Government has launched its New Southbound Policy to attract more international students (Lin, 2020). However, there is limited 
research about Vietnamese international students' satisfaction in Taiwan's universities. And since Vietnamese students constitute the main source of international students in Taiwan, their needs and satisfaction are an essential research question. Therefore, this paper aims to understand better factors constituting Vietnamese students' satisfaction with learning and living environment in Taiwan universities. Also, this paper will explore the different perceptions of satisfaction among Vietnamese international student groups: Scholarship-sponsored students and self-supporting students. The findings from this paper might provide novel insight into the field of higher education service quality by providing a contextual understanding of Vietnamese international students' perception of satisfaction relating to learning and living environment in Taiwan universities. This is because there is lack of exploring study on international students in host countries (Jiang, Yuen, \& Horta, 2020). Also, it could provide practical implications to university leaders and policymakers concerning marketing strategy design attracting more Vietnamese international students to select Taiwan universities as the best destination for their higher education.

The rest of this paper is structured as below. Firstly, this paper reviews previous studies relating to this field to develop the research questions. Secondly, the research design is presented and described in detail. Thirdly, this paper presents the findings. Fourthly, discussions are provided. Finally, it presents the conclusions.

\section{Literature review}

The definition of satisfaction and customer satisfaction was mentioned in many studies for years. According to marketing literature, satisfaction refers to a persons' approval or disappointment when comparing their personal opinion of services received with their original service expectations (Fonseca, 2009; Kotler, 1995). Regarding to higher education services, students' satisfaction is defined as the student's fulfillment response (Anderson, Fornell, \& Rust, 1997). The individual overall subjective evaluation and experience of a product/service feature, the product/service itself, and between what was received and what was expected from a specific service provider to date (Anderson et al., 1997; Oliver, 1999).

In fact, there are various studies on students' satisfaction with higher education service. Aldridge and Rowley (1998) measured customer satisfaction in higher education and identified five important factors that influenced students' satisfaction such as college/personal tutor system, good food at reasonable prices, publicity of rights in relation to student's union, training opportunities for students serving on committees, and opportunities to feedback on course and service provision through questionnaires. Meanwhile, some other studies showed that university image, textbooks, being female, and informed before attending university are considered important factors of satisfaction (Aldemir \& Gülcan, 2004; Palacio, Meneses, \& Perez, 2002). Butt and Rehman (2010) examined the students' satisfaction in higher education in Pakistan based on four factors: teacher's expertise, the course offered, learning environment, and classroom facilities. The results revealed that all attributes had a significant and positive impact on students' satisfaction with varying degrees of strength in which the factor teacher's expertise was the most influential. Remarkably, studies on students' satisfaction have expanded in many subjects, especially international students in host countries, who come to different countries to study and experience new cultures. Thus, their satisfaction is influenced by factors from inside and outside the campus, such as education, social, technology, economics, accommodation, safety, prestige, and image (Arambewela \& Hall, 2007). Similarly, Brux and Fry (2010) suggested that international students consider abroad education as an investment channel. They emphasize such factors as reputation, quality of academic staff, course content, program-related 
issues, costs, delivery of services, and management's concern for them. Therefore, depending on the difference of culture and motivation, international students perceive higher education services as important for their satisfaction with their host university. Recently, Jiang et al. (2020) findings show that international students' satisfaction in China universities is very contextual and includes the course quality, languages (both English and Chines), support, and counseling services. This study also identifies the different perception of satisfaction in higher education among international students from different cultures, types of studies (scholarship-sponsored and self-supporting students), and level of study.

To sum up, international students' satisfaction with universities in host counties is influenced by various factors. While the percentage of Vietnamese international students in Taiwan universities has increased, it is still unknown on their perception of satisfaction. To address the gap of research on Vietnamese international student satisfaction in Taiwan universities, this study aims to answer three research questions as below:

1) What factors impact Vietnamese students' satisfaction in Taiwan universities? An exploratory study with qualitative research will be utilized to answer this research question. Flick (1998) showed that qualitative research should be employed for an analysis in which the research questions ask about 'what', since this kind of research is seeking to explore a problem or issue;

2) How these factors impact Vietnamese students' satisfaction in Taiwan universities? To answer this research question, this study employed quantitative approach with descriptive analysis;

3) Is there a difference of perceived satisfaction among Vietnamese international student groups (gender, type of sponsored study) in Taiwan universities? To gain answers for this research question, quantitative research was also applied with an Independent- Sample T-test.

\section{Research methodologies}

Given that this study explores research to have an in-depth understanding of the issue, the research was designed into two stages (Study 1 and Study 2). The first stage (Study 1 as a preliminary stage in quantitative study) was a qualitative approach with two rounds of studies: Round 1- group discussion, and round 2- open-ended survey questions. The second stage (Study 2) was a quantitative approach with a survey of 192 respondents. This sample size is adapted from previous studies' suggestions (MacCallum, Widaman, Zhang, \& Hong, 1999).

\subsection{Study 1: Exploring factors of Vietnamese student satisfaction in Taiwan universities}

\subsubsection{Methods}

This first stage of study aims to explore factors that impact Vietnamese student satisfaction in Taiwan universities. In order to attain objective and positive results, the study has carried out two rounds of research in this first stage (Study 1). The first round was a focus group discussion with 10 students at Minghsin University of Science and Technology, having the highest number of Vietnamese international students in Taiwan universities at the time of this study conducted.

In this discussion, students were encouraged to share their perception of satisfaction in Taiwan universities and identify factors determining their satisfaction and/or dissatisfaction. The findings of the focus group showed that five common perceived factors impacting Vietnamese student satisfaction include instructor, learning material, facility, dormitory service, and extracurricular activity. 
The second round was utilized to seek the details of these five factors with open-ended survey questions. These questions were relating to five factors gaining from focus group discussion, for example, 'Why do you think that instructor of the university has influenced your satisfaction in Taiwan university?', 'Why do you think that learning material of the university has influenced your satisfaction in Taiwan university?', 'Why do you think that facilities of the university have influenced your satisfaction in Taiwan university?', 'Why do you think that dormitory services of the university have influenced your satisfaction in Taiwan university?', 'Why do you think that the university's extracurricular activities have influenced your satisfaction in Taiwan university?' Also, another question was incorporated into the survey such as 'Is there anything else you want to add on about your satisfaction in Taiwan university?' The open-ended survey questions were delivered to 20 Vietnamese students via their emails. This procedure was supported by the Association of Vietnamese International Students in Taiwan as they provided the author the list of student emails. Participants for this round of the first stage (Study 1) of this study were asked freely to write down their answers and sent them back to the author to address the ethical issues of the study (Creswell, 2007). The thematical technique was utilized to analyze the data at this stage.

\subsubsection{Results of study 1}

As showed in "Table 1", 24 themes as attributes of 05 factors were identified (five attributes describing 'instructor', six attributes describing 'learning material', four attributes showing 'facility', five attributes describing 'dormitory service', and four attributes describing 'extracurricular activity'). Most attributes found from this qualitative study are similar to previous studies' results as presented in column 03 (see "Table 1"). However, after crosschecking each factor to prior studies, two separate factors (learning materials, facility) were integrated into one factor 'learning materials and facility'.

\section{Table 1}

Findings from Study 1 about five factors of Vietnamese student satisfaction

\begin{tabular}{|c|c|c|}
\hline Themes & Coding categories & Comparing with previous studies \\
\hline \multirow[t]{5}{*}{ Instructor } & Content of lectures & - Teachers expertise and their interest in their \\
\hline & Opportunities for discussion & subject (Mai, 2005) \\
\hline & $\begin{array}{l}\text { Opportunities for } \\
\text { presentation }\end{array}$ & $\begin{array}{l}\text { - Opportunities to feedback on course } \\
\text { (Aldridge \& Rowley, 1998) }\end{array}$ \\
\hline & $\begin{array}{l}\text { Availabilities of instructors } \\
\text { outside class }\end{array}$ & $\begin{array}{l}\text { - Fair treatment from professors; the teaching } \\
\text { and content of their courses (Calderwood, }\end{array}$ \\
\hline & Fair grading policy & \\
\hline \multirow{6}{*}{$\begin{array}{l}\text { Learning } \\
\text { material }\end{array}$} & Sufficient quantity & - Library, literature and lecture materials, \\
\hline & Appropriate content & relevant and up to date literature and lecture \\
\hline & Library resources & \\
\hline & Easy understood & \\
\hline & Useful & \\
\hline & Up today & \\
\hline \multirow[t]{2}{*}{ Facility } & $\begin{array}{l}\text { The availability of computer } \\
\text { and internet access }\end{array}$ & $\begin{array}{l}\text { - The quality and accessibility of IT facilities } \\
\text { (Mai, 2005) }\end{array}$ \\
\hline & Lab equipment & - Computer and Internet, learning equipment \\
\hline
\end{tabular}




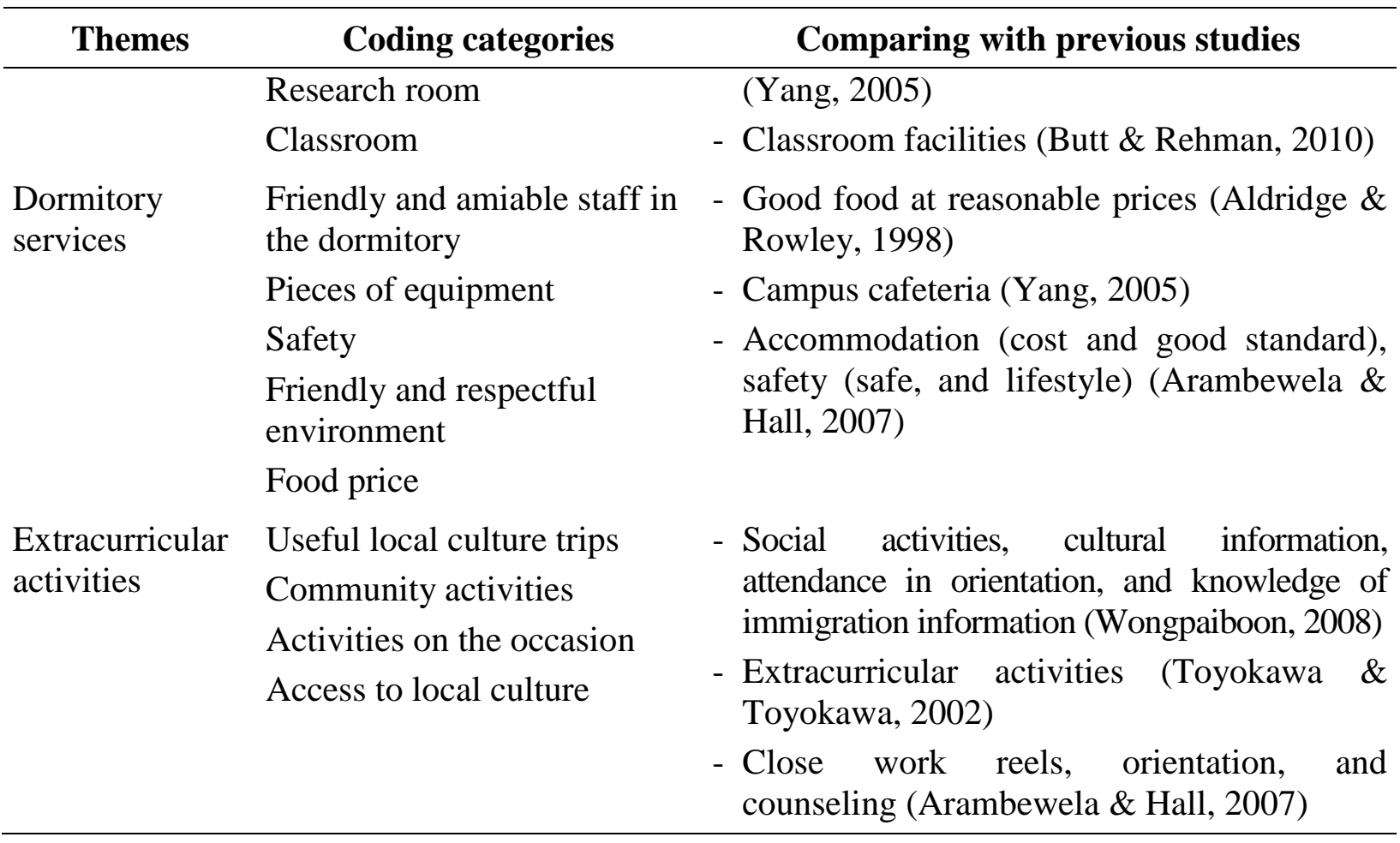

Source: The author's theme summary

The findings from this Study 1 were utilized to design questionnaires for the second study. The attributes (themes) gained from Study 1 were developed as constructs of each question in the questionnaire.

\subsection{Study 2: Measuring factors of Vietnamese students' satisfaction in Taiwan universities}

This stage (Study 2) of the study used quantitative research with a survey of 192 respondents. To do so, a questionnaire of 28 questions was designed and developed from Study 1 (the results of qualitative studies) and the previous studies (i.e., Aldridge \& Rowley, 1998; Mai, 2005; Yang, 2005). This questionnaire was divided into 04 parts. But, in this paper, the author only reported the findings from two parts. Another part has been published on Journal of Science and Technology (Alang, 2012). Questions of the first part of this questionnaire were used to collect personal information such as gender, level of study, source of financial support, and academic performance. In this questionnaire, measuring respondents' academic performance was based on a letter grade system (A, B, C, D, E), which addresses the Taiwan university system's performance evaluation. Each letter grade was linked to a range of grade system presented as below: A (ranging from 87 to 100), B (ranging from 77 to 87), C (ranging from 67 to 77), D (ranging from 57 to 67), E (under 57). The respondents were asked to select their overall letter grades according to their actual performance in the previous semester.

In the second part, this study used 5-point Likert scale (including 'strongly disagree', 'disagree', 'neutral', 'agree', and 'strongly agree') to examine student satisfaction on four related factors. There were five constructs of 'instructor' factor (i.e., the content of lectures, teaching capacity, student participation in-class activities, availability of instructor outside the class time, and grading policy); four constructs of 'learning materials and facility' (i.e., the contents of teaching materials, library resources, accessibility of Internet and computer, and classroom facility); four constructs of 'dormitory services' (i.e., staff in the dormitory, dormitory facility, safety, canteen services); four constructs of 'extracurricular activity' (i.e., extracurricular 
activities on holidays, access to local culture, accessible to local students, and orientation programs). The questionnaire was designed in English and translated into Vietnamese. Four Vietnamese students with good English ability checked the wording and meaning in order to ensure that they were appropriate for the Vietnamese cultures.

The research subjects of this study were Vietnamese international students studying in Taiwan's universities with undergraduate, master, and doctoral levels. Moreover, the respondents could have at least one year of living experience in Taiwan to qualify for the survey. This study employed a stratified sampling technique, in which each university that had Vietnamese student enrolment was considered as a group. This stratified sampling would cover representatives of Vietnamese students from all Taiwan universities. Thanks to the support of the Vietnamese Student Association, the questionnaires were direct delivered to all Vietnamese student groups in 20 Taiwan universities. Also, the questionnaires were sent through Vietnamese students' email, Facebook, yahoo messenger, and blog. The data was collected over five weeks. The data was analyzed and checked through several statistical tools, including Cronbach's alpha, exploratory factor analysis (EFA), and descriptive analysis using SPSS 20.

\section{Results}

\subsection{Respondents' demographic profiles}

This study collected data from 500 subjects representing approximately 3,500 Vietnamese students studying in Taiwan's universities in 2012. However, there were only 192 useable responses represented an acceptable 69\% response rate from 13 universities, including Minghsin University of Science and Technology, Chung Hua University, Chung Yuan Christian University, I Shou University, Ming Chuan University, Southern Taiwan University, Yu Da University, Yuan Ze University, National Kaohsiung University of Applied Science, National Chung Hsing University, National Cheng Kung University, National Chiao Tung University, and National Pingtung University of Science and Technology. Concerning gender, there were $61.5 \%$ of male and $38.5 \%$ of female respondents. There were $63.5 \%$ undergraduate students, $30.7 \%$ Master students, and 5.7\% Ph.D. students in terms of education levels. Particularly, it was interesting to note that $60.9 \%$ of respondents studied in Taiwan universities by their familysupporting finance. These statistics suggest that this sample is a significant representative of Vietnamese international students in Taiwan universities at the time of this study. This meant the findings from this sample is reliable and generalizable.

\subsection{Measurement reliability and validity}

Given that this is an exploratory study, and the questionnaire was designed based on the results of qualitative research from Study 1, it is essential to test the reliability and validity of these measurement scales. According to Wells and Wollack (2003), to gain the internal consistency of measurement scales, Cronbach's Alpha and Composite Reliability should be higher than 0.7. As presented in "Table 2", the Cronbach's Alpha of all constructs ranges from 0.720 to 0.869 . The Composite Reliability of these five factors ranges from 0.733 to 0.780 . Also, with $\mathrm{KMO}=0.918$ (p-value $<0.01$ ), cumulative $\%=73 \%$, these findings have statistical significance, and the measurement scales used fit the data well. Particularly, these four factors explained $73 \%$ of the variation of data. The measure's validity was also significantly addressed as the values of Average Variances Extracted of four factors (ranging from 0.723 to 0.755 ) were higher than 0.5 (Fornell \& Larcker, 1981). Likewise, as showed in "Table 3" the values of estimated correlations among four factors (ranging from 0.707 to 0.877 ) were strong, which suggests the discriminant validity between each pair of variables (Wells \& Wollack, 2003). Overall, the measurement model results were satisfactory. 


\section{Table 2}

Measurement scales reliability and validity

\begin{tabular}{cccccc}
\hline Attributes & $\begin{array}{c}\text { Factor } \\
\text { loadings }\end{array}$ & Means & $\begin{array}{c}\text { Cronbach's } \\
\text { Alpha }\end{array}$ & $\begin{array}{c}\text { Composite } \\
\text { Reliability }\end{array}$ & $\begin{array}{c}\text { Average Variances } \\
\text { Extracted }\end{array}$ \\
\hline Instructor & & & & & \\
INS1 & 0.796 & & & & \\
INS2 & 0.780 & 4.37 & 0.773 & 0.740 & \\
INS3 & 0.720 & & & & \\
INS4 & 0.723 & & & & \\
INS5 & 0.815 & & & & \\
Learning materials and & & & & & \\
facility & 0.750 & & & & \\
LMF1 & 0.811 & 3.52 & 0.796 & \\
LMF2 & 0.759 & & & & \\
LMF3 & 0.869 & & & & \\
LMF4 & & & & \\
Dormitory services & & & & \\
DOM1 & 0.733 & & & \\
DOM2 & 0.745 & 3.80 & 0.724 & \\
DOM3 & 0.761 & & & & \\
DOM4 & 0.731 & & & & \\
Extracurricular activity & & & & \\
EXT1 & 0.768 & & & & \\
EXT2 & 0.769 & 3.91 & & \\
EXT3 & 0.760 & & & & \\
EXT4 & 0.813 & & & & \\
\hline
\end{tabular}

Source: The author's data analysis

\subsection{Vietnamese international student satisfaction in Taiwan universities}

The findings revealed that Vietnamese students are satisfied with four factors of Taiwan higher education (i.e., means of all factors were higher than 3.5) (see "Table 2"). In particular, an instructor with five constructs gained the highest point of student satisfaction with Mean $=4.37$, in which content of lectures had Mean $=4.57$, teaching capacity had Mean $=4.40$, student participation in class activities had Mean $=3.90$, availability of instructor outside the class time had Mean $=4.37$, and grading policy had Mean $=4.6$. The extracurricular activity gained the second-highest point of student satisfaction with Mean $=3.91$. Four constructs of this extracurricular activity included off-school activities on holidays (Mean $=4.20$ ), accessible to local culture $($ Mean $=3.9)$, accessible to local students (Mean $=3.05)$, and orientation programs $($ Mean $=4.50)$. The third place was dormitory services with Mean $=3.80$. Four constructs of this dormitory service included staff in dormitory (Mean $=3.88$ ), dormitory facility (Mean = 2.99), safety $($ Mean $=4.6)$, canteen services $($ Mean $=3.73)$. Learning material and facility had the relatively lower point of student satisfaction with Mean $=3.52$, in which the contents of teaching materials gained Mean $=2.99$, library resources had Mean $=4.00$, accessibility of internet and computer had Mean $=3.84$, and classroom facility had Mean $=3.24$. 


\section{Table 3}

Correlation and discriminant validity

\begin{tabular}{lcccc}
\hline \multicolumn{1}{c}{ Factors } & Instructor & $\begin{array}{c}\text { Learning material } \\
\text { and activity }\end{array}$ & $\begin{array}{c}\text { Dormitory } \\
\text { service }\end{array}$ & $\begin{array}{c}\text { Extracurricular } \\
\text { activity }\end{array}$ \\
\hline $\begin{array}{l}\text { Instructor } \\
\text { Learning material and } \\
\text { activity }\end{array}$ & $\mathbf{( 0 . 7 3 9 )}$ & & & \\
Dormitory service & $0.769^{* *}$ & $\mathbf{( 0 . 7 8 0 )}$ & & \\
Extracurricular activity & $0.877^{*}$ & $0.707^{*}$ & $\mathbf{( 0 . 7 4 0 )}$ & \\
\hline
\end{tabular}

Source: The author's data analysis

Note: $\mathrm{p}$-value ${ }^{*}<0.05, \mathrm{p}$-value ${ }^{* *}<0.01$

\subsection{Comparing Vietnamese international student satisfaction among student groups}

The study divided the samples into two groups based on their gender and financial support source to analyze and compare the findings. Firstly, it is evident that female students are quite different from males for many aspects of perceived satisfaction of a living condition, learning condition, and so forth. Normally, female students are easier to access to satisfaction. However, the finding of the Independent- Sample T-test from this study showed that there is not any statistical significance.

Secondly, the fundamental differences of perceived satisfaction came from the scholarship-sponsored students and self-supporting students (i.e., who study by their families' finance support in Taiwan universities). As mentioned early, the study sample includes $33.8 \%$ of scholarship-sponsored students and $60.9 \%$ of self-supporting students. As showed in "Table 4", the results of Independent - Samples T-test analysis had statistical significance with 3 of 5 variables examined, such as students' learning performance (P-value $<0.001$ ), satisfaction with the instructor (P-value $<0.001)$, satisfaction with learning material and facility (P-value $<0.05)$. These findings revealed that scholarship-sponsored students achieve higher grades (mean $=4.4$ nearly level A) than self-supporting students (mean $=3.27$ equivalently level C). They also had a different perception of satisfaction. Scholarship-sponsored students had lower satisfaction points with both instructor (Mean = 3.44) and learning material and facility (Mean = 3.63). Meanwhile, self-supporting students expressed more satisfaction with the instructor (Mean = 3.82) and learning material and facility (Mean $=3.89$ ).

\section{Table 4}

The results of Independent-Samples T-test for student groups

\begin{tabular}{lcccc}
\hline & Scholarship-sponsored & Self-supported & t & Sig. \\
\hline Academic performance & 4.40 & 3.27 & 10.139 & $0.000^{* *}$ \\
Instructor & 3.44 & 3.82 & -3.075 & $0.0024^{* *}$ \\
Learning material and facility & 3.63 & 3.89 & -2.186 & $0.0301^{*}$ \\
Dormitory service & 3.75 & 3.59 & 1.393 & 0.1653 \\
Extracurricular activity & 3.52 & 3.73 & -1.582 & 0.1154 \\
\hline
\end{tabular}

Source: The author's data analysis

Note: p-value ${ }^{*}<0.05$, p-value ${ }^{* *}<0.01$ 


\section{Discussion}

This study addressed three research questions concerning Vietnamese international students' satisfaction in Taiwan universities. Firstly, this study determined four main factors constituting Vietnamese international students' satisfaction: instructor, learning material and facility, dormitory service, and extracurricular activity. These findings are relatively similar to previous studies. For example, relating to the instructor, previous studies also found that quality of academic staff, course content, and program-related issues play as significant aspects of international students' satisfaction with the university in the host countries (Calderwood, 1993). The interesting and different points from this present study are that Vietnamese international students considered the opportunity to participate in classroom activities, and the support of their instructor beyond the classroom time was vital to them. Regarding learning material and facility, in a similar vein with previous studies, this study suggests that the contents of teaching materials, library resources, accessibility of the Internet and computer, and classroom facilities are constituted the student satisfaction with university services (Butt \& Rehman, 2010; Mai, 2005; Yang, 2005). This present study also suggests that dormitory services including the support of housing staff within the dormitory, dormitory equipment (e.g., air conditioner, water heater, television, refrigerator, bed, laundry, gym, etc.), security, and canteen services (e.g., variety of food, delivery services, etc.) should be taken into consideration because they are key determinants of Vietnamese students' satisfaction. The last but not least factor of Vietnamese international students' satisfaction in Taiwan universities is extracurricular activities that include off-school activities on holidays, accessibility to local cultures, accessibility to local students, and orientation programs. These findings are supported by previous studies such as Jiang et al. (2020), Toyokawa and Toyokawa (2002), and Arambewela and Hall (2007).

Secondly, this study found that all factors significantly impacted Vietnamese international students' satisfaction in Taiwan universities. Particularly, Vietnamese international students were very much satisfied with the academic staff in Taiwan universities. They evaluated Taiwanese instructors as excellent at lectures, teaching capacity, support outside the classroom, and clear and fair grading policy. The instructors also addressed the student needs for participation and involvement in classroom activities. Other factors were considered relatively high impacts on Vietnamese international students' satisfaction, including off-school activities on holidays, orientation programs, accessibility to the local cultures, dormitory security, library resources, the support of housing staff at the dormitory, and the accessibility of the Internet and computer on the campus. Besides that, several aspects of Taiwan universities were not addressed well the Vietnamese international students' expectations, which would reduce their perception of satisfaction. These include the accessibility to local students and communities, dormitory equipment, canteen services, the contents of teaching materials, and classroom facilities.

Thirdly, there are differences of perceived satisfaction among student groups of Vietnamese international students in Taiwan universities. This study found that, as compared to self-supporting students, Vietnamese international students who received a scholarship from Taiwan universities and Taiwan Government to study in Taiwan universities expressed relatively lower satisfaction with their instructors, and learning materials and facility even though their academic performance was higher than that of self-supporting students. It could be explained that most scholarship-sponsored students, who were selected by the scholarship to study in Taiwan, are talented students in high schools of Vietnam and/or they had been university lecturers or government officials. With that status, these scholarship-sponsored students might have high expectation on living and learning environment in Taiwan. 


\section{Conclusions}

This study suggested four factors determining Vietnamese international students' satisfaction in Taiwan universities: instructor, learning material and facility, dormitory service, and extracurricular activity. Practitioners and policymakers could be considered these factors as the input into their decision-making to improving the status quo of international students' satisfaction in universities and designing marketing strategies of Vietnamese international student recruitment. While Taiwan universities have addressed well Vietnamese international students' expectations relating to the instructor, dormitory service, and extracurricular activity, it is suggested that improvement is needed with learning materials and facilities. For example, to increase Vietnamese international student satisfaction with these learning materials, Taiwan universities should give Chinese training courses to Vietnamese students, particularly freshmen. This may support them in easily accessing Chinese materials (E-library, E-learning, Newspapers, Textbook, Research journals, Magazine) and using onsite facilities. Also, given that scholarshipsponsored students had relatively lower levels of satisfaction with instructors and learning materials and facilities, it is suggested that Taiwan universities should look through their issues and give support. Since these scholarship-sponsored students had good learning performance and would have potential contributions to the universities concerning expanding the universities' partnership network. This is because most scholarship-sponsored students were university lecturers in Vietnam, and they would play a bridge role among Taiwan universities and Vietnam Government.

The limitations of this study are recognized. First, the sample size for study 1 using qualitative research was relatively small. That would be limited the initial ideas to exploring the issues and generalization of the findings. However, it was rich and deep data and gained support from Study 2 as quantitative approaches. Second, with Study 2, this study used mostly descriptive methods to explain the levels of satisfaction concerning each factor. It suggests that future research should focus on developing relevant hypotheses, measuring these factors as independent variables, and testing the impact of these factors on overall satisfaction (playing as a dependent variable). Hence, regression analysis could be highly recommended for further research. Third, this study found that students based on their study levels and finance supports of study in Taiwan universities have significantly impacted their satisfaction. Hence, it is essential to examine these factors as moderating and/or mediating factors influencing the relationship between these four factors and Vietnamese international students' overall satisfaction in Taiwan universities. Fourth, it suggests that future research should extend the research scope and subjects to all international students in Taiwan universities instead of a single country; by doing so, the findings would be globally generalizable.

\section{ACKNOWLEDGMENTS}

I would like to thank Dr. Shuyeu Lin for his earlier comments and feedback on this study. Also, I would like to express my gratitude to the Association of Vietnamese International Students in Taiwan, the editors, and reviewers of this journal for their support and encouragement.

\section{References}

Alang, T. (2012). Application of importance - Performance analysis to examining student satisfaction: Evidence from Vietnamese students in Taiwan's universities. Journal of Science and Technology, 12(61), 168-173. 
Aldemir, C., \& Gülcan, Y. (2004). Student satisfaction in higher education: A Turkish case. Higher and Education Management and Policy, 16(2), 109-122.

Aldridge, S., \& Rowley, J. (1998). Measuring customer satisfaction in higher education. Quality Assurance in Education, 6(4), 197-204.

Anderson, E. W., Fornell, C., \& Rust, R. T. (1997). Customer satisfaction, productivity and profitability: Differences between goods and services. Marketing Science, 16(2), 129-145.

Arambewela, R., \& Hall, J. (2007). A model of student satisfaction: International postgraduate students from Asia. In S. Borghini, M. A. McGrath \& C. Otnes (Eds.), E-European advances in consumer research (pp. 129-135). Duluth, MN: Association for consumer research.

Butt, B. Z., \& Rehman, K. (2010). A study examining the student satisfaction in higher education. Procedia Social and Behavioral Sciences, 2(2), 5446-5450.

Calderwood, D. (1993). International students at Alberta universities: Perceptions and levels of satisfaction (Master's thesis). University of Lethbridge: Alberta, Canada.

Creswell, J. W. (2007). Qualitative inquiry \& research design: Choosing among five approaches (2nd ed.). Thousand Oaks, CA: SAGE.

DeShields, Jr., Kara, O. W., \& Kaynak, E. (2005). Determinants of business student satisfaction and retention in higher education: Applying Herzberg's two factor theory. International Journal of Educational Management, 19(2), 128-139.

Firdaus, A. (2005). HEdPERF versus SERVPERF: The quest for ideal measuring instrument of service quality in higher education sector. Quality Assurance in Education, 13(4), 305-28.

Flick, U. (2018). An introduction to qualitative research. London, UK: SAGE.

Fonseca, J. R. S. (2009). Customer satisfaction study via a latent segment model. Journal of Retailing and Consumer Services, 16(5), 352-359.

Fornell, C., \& Larcker, D. F. (1981). Evaluating structural equation models with unobservable variables and measurement error. Journal of Marketing Research, 18(1), 39-50.

Gallifa, J., \& Batallé, P. (2010). Student perceptions of service quality in a multi-campus higher education system in Spain. Quality Assurance in Education, 18(2), 156-170.

Jiang, Q., Yuen, M., \& Horta, H. (2020). Factors influencing life satisfaction of international students in Mainland China. International Journal for the Advancement of Counselling, 42(4), 393-413.

Kotler, P. (1995). Strategic marketing for educational institutions. London, UK: Prentice-Hall.

Lin, A. F. Y. (2020). Internationalization initiatives of Taiwan's higher education: A stepping stone to regional talent circulation or reproduction of unbalanced mobility scheme? Higher Education Evaluation and Development, 14(2), 69-91.

MacCallum, R. C., Widaman, K. F., Zhang, S., \& Hong, S. (1999). Sample size in factor analysis. Psychological Methods, 4(1), 84-99.

Mai, L. W. (2005). A comparative study between UK and US: The student satisfaction in higher education and its influential factors. Journal of Marketing Management, 21(7/8), 859-878.

Ministry of Education Republic of China (Taiwan). (2021). International students come together to Taiwan, where the one-hundred thirty thousand overseas student mark has been passed. Retrieved June 18, 2021, from https://english.moe.gov.tw/cp-117-25416-d8868-1.html 
Brux, J. M., \& Fry, B. (2010). Multicultural students in study abroad: Their interests, their issues, and their constraints. Journal of studies in International Education, 14(5), 508-527.

Oliver, R. L. (1999). Whence consumer loyalty? Journal of Marketing, 63(4), 33-44.

Oliver, R. L., \& Rust R.T. (1997). Customer delight: Foundations, findings, and managerial insight. Journal of Retailing, 73(3), 311-36.

Palacio, A. B., Meneses, G. B., \& Perez, P. J. P. (2002). The configuration of the university image and its relationship with the satisfaction of students. Journal of Educational Administration, 40(5), 486-505.

Taiwan News. (2020). Vietnamese students in Taiwan increase by 330\% over 3 years. Retrieved June 18, 2021, from https://www.taiwannews.com.tw/en/news/4088611

Toyokawa, T., \& Toyokawa, N. (2002). Extracurricular activities and the adjustment of Asian international students: A study of Japanese students. International Journal of Intercultural Relations, 26(4), 363-379.

Wells, C. S., \& Wollack, J. A. (2003). An instructor's guide to understanding test reliability. Testing \& Evaluation Services. Madison, Wisconsin: University of Wisconsin.

Wongpaiboon, K. (2008). A study of international student satisfaction with the academic environment, social environment, and services of international programs for student's office at the University of South Carolina, Columbia Campus (Doctoral dissertation, University of South Carolina, Columbia, SC).

Yang, C. C. (2005). The refined Kano's model and its application. Total Quality Management, 16(10), 1127-1137. 